\title{
Relativizing the Relativized A Priori: Reichenbach's Axioms of Coordination Divided
}

\author{
Flavia Padovani \\ HPS, University of Geneva / Centre for Philosophy of Science, Pittsburgh
}

February 2009

\begin{abstract}
In recent years, Reichenbach's 1920 conception of the principles of coordination has attracted increased attention after Michael Friedman's attempt to revive Reichenbach's idea of a "relativized a priori". This paper follows the origin and development of this idea in the framework of Reichenbach's distinction between the axioms of coordination and the axioms of connection. It suggests a further differentiation among the coordinating axioms and accordingly proposes a different account of Reichenbach's "relativized a priori”.
\end{abstract}

Keywords: Relativized a priori, axioms of coordination, probability, causality, Reichenbach, Cassirer, Friedman.

\section{Introduction}

In the years he spent in Istanbul, between 1933 and 1938, Reichenbach was mainly engaged in providing a more solid framework for the probabilistic picture he had started delineating in his doctoral dissertation of 1915, namely a probabilistic logic for scientific thought. ${ }^{1}$ These years are also characterised by his final attempt to refute the synthetic a priori, when he coined the pregnant expression "disaggregation (désagrégation) of the a priori" to describe the movement of ideas that led to the birth of logical empiricism. ${ }^{2}$ Nonetheless, nowadays one of his most discussed, and certainly most interesting, contributions is considered to be the original proposal of a synthetic (or constitutive) yet revisable a priori, which he 
first formulated in his 1920 "Habilitation" thesis on relativity theory and cognition a priori. $^{3}$

In this work, which deals with the possibility of reconciling Einstein's theory with the Kantian system, the notion of constitutive a priori appears to be tied to a view of the cognitive coordination (Zuordnung) that is in general traced back to the influence of Moritz Schlick's General Theory of Knowledge (1918). In fact, in the secondary literature, it is largely accepted that Reichenbach first proposed a peculiar version of the synthetic a priori-and its correlated concept of cognitive coordination - only after his encounter with relativity theory, in the years 19171920. ${ }^{4}$ As Friedman puts it,

[i]t is in no way accidental that coordination as a philosophical problem was first articulated by scientific philosophers deliberately attempting to come to terms with Einstein's general theory of relativity. Indeed, Reichenbach in 1920, together with Moritz Schlick in virtually contemporaneous work, were the first thinkers explicitly to pose and to attempt to solve this philosophical problem. [Friedman (2001), 78]

The aim of the present paper is to discuss neither Friedman's proposal of a relativized a priori, nor the way he used it to ground his dynamical conception of the scientific development and its related philosophy from Newton to Einstein. Rather, it is to analyse and clarify Reichenbach's conception of cognitive coordination in his early works in order to show that what he had in mind was more sophisticated than usually suggested and was also crucially linked with the role he assigned to probability in scientific representation.

A philosophical framework for the notion of coordination, as functional correlation between a concept and its object, was indeed first provided by Reichenbach not with respect to the theory of relativity, and not primarily in line with Schlick's 1918 conception, but against a totally different background, namely probabilistic, in his doctoral dissertation of 1915, The Concept of Probability in the Mathematical Representation of Reality. ${ }^{5}$ The fact that the issue of coordination makes its first appearance in such a framework is important in that the core of the relativized a priori is to be found, in nuce, in his doctoral thesis, not in his monograph on relativity theory. Moreover, as we shall see, Reichenbach's concept of Zuordnung is mainly inspired by the one Cassirer elaborated in his "Kant und die moderne Mathematik" (1907) and in Substance and Function (1910).

In the next section, I will briefly sketch some of the features of Reichenbach's first work on probability and emphasise that this was the real ground of his move away from Kant, focussing on the specificity of his formulation of coordination. In section 3, I will consider the way this notion is imported into his "Habilitation" 
thesis, where it turns into the distinction between axioms of coordination and axioms of connection. Finally, in section 4, I will present some developments related to this distinction that Reichenbach considered right after the publication of his 1920 book and that imply a different reading of his relativized a priori. These developments are prior to the well-known correspondence with Schlick of the end of November 1920, which has in general been deemed the principal cause of Reichenbach's adoption of a "conventionalist" viewpoint. In my view, two levels of constitutivity can be identified in his original proposal, along, so to speak, a vertical axis, as I suggest in the last section. This allows for an interpretation that regards his later shift towards conventionalism as only partial.

\section{Elements of an Attempted "(Neo-)Kantian" Pro- posal}

\subsection{Coordination in the Dissertation. Or: From Mathematics to Physics (via an Account of Approximations)}

Reichenbach's doctoral thesis initiated a reflection on the principles of causality and probability that he was bound to develop over the course of his entire intellectual life. ${ }^{6}$ In his first work, Reichenbach emphasised the importance of these two fundamental principles of knowledge, which appear to be compatible and whose validity is traced back to their status as synthetic a priori principles in the traditional Kantian fashion. ${ }^{7}$ In this work, the importance of the principle of probability is crucially linked with that of the principle of causality, which in 1915 Reichenbach still considered as complemented by the principle of probability.

Following Kant, Reichenbach views the physical laws as describing (causal) connections among natural phenomena. These connections can be conceived, and are indeed justified, only by virtue of a synthetic a priori principle: the principle of causality, here also called "the principle of the lawful connection" (Prinzip der gesetzmässigen Verknüpfung). Physical laws are expressed in mathematical terms. The application of mathematical laws entails their coordination to empirical quantities, as represented in the physical equations. However, these quantities are never as exact as the quantities that enter into pure mathematics because they are scattered around certain values that need to be estimated. In this respect, the values that occur within physical laws are "fictions" in the sense that they do not mirror reality perfectly but merely with a certain, possibly high, degree of accuracy. Every physical law (every causal assertion) presupposes a neglect of certain perturbing factors that are ineliminable from the observation. Since there are an infinite number of such factors, it is impossible to determine their precise values. 
Therefore, we have to make some hypothesis concerning the behaviour of these perturbations and their frequency.

The idea is as follows. Our measurements are in principle imprecise. The measured values should represent the algebraic sum of an infinity of influential quantities, but for practical reasons, we have to consider them as the sum of finite factors, which we can use to calculate "backwards" the sought quantity. Our direct measurement, explains Reichenbach, never points to the real quantity that we are supposed to find, but only to its function. In this sense, the resulting numerical value is the one that we have chosen as representative for the class of available measured values. So the problem is that of being able to determine which of these values is the "correct" one. In other words, we have to find a lawful procedure to ground the choice among these various possibilities. This procedure is represented by a mathematical law expressing the errors distribution, a law that will "assign a frequency to every error." 8 This is the role played by the other fundamental synthetic a priori principle, which Reichenbach defines as the "principle of the lawful distribution" (Prinzip der gesetzmässigen Verteilung), i.e., the principle of probability. This principle asserts that each empirical distribution has a convergence limit, and it warrants (via a "transcendental" justification) $)^{9}$ that the observed convergence in the empirical distribution actually is representative of the "true" probabilities. This should finally enable us to formulate the physical laws, therefore making possible a prediction. Thus, Reichenbach's principle of probability is meant to complete Kant's principle of causality. ${ }^{10}$

It is in this context that Reichenbach first uses the concept of coordination to express the idea that the content of physical knowledge requires some specific form of coordination of certain mathematical structures to objects of empirical intuitions. Whereas the objects of mathematical judgments can be fully grasped, the objects of physical judgments require the coordination of the former to the unformed reality in order to produce the latter. In doing so, Reichenbach implicitly underlines that - the methodical Kantian assertion concerning the applicability of mathematics to the physical world notwithstanding - this coordination is in principle not complete, as we cannot do without approximations: a stance which is quite far from the Kantian spirit. ${ }^{11}$

In the coordination of the mathematical structures to real ones required by physics (as well as by any empirical science), an important part is therefore played by the approximations with which we have to deal when we want to lay out natural laws. The values that appear within physical equations never stand for the measured values, which merely approximate the "real" ones (those which indeed satisfy the equations): hence, the crucial importance of probability in natural sciences. Physical knowledge, Reichenbach writes,

consists in the coordination of equations, and consequently of 
numbers, to classes of objects of empirical intuition. The equality of these numbers for a number of actual objects of the class cannot be asserted, but only the approximate equality. The reason for this approximation is the existence of a law for the distribution of values. While mathematical judgments determine variables in such a way that they are the same for all their individual objects in all places at all times, the variables in a physical judgment are not equal for all individual objects in their class, but rather subject to a law of distribution in space and time. Instead of the general validity of mathematical claims, we have in the case of physical judgments the subsumption under the law of distribution. [Reichenbach (1916/2008), 127]

In Reichenbach's doctoral thesis, physical (but, in general, any empirical) knowledge puts forward an assertion about the validity of the coordination of a specified mathematical structure to reality. Thereby, with respect to the Kantian tradition, the question of validity is raised around two axes. On the one hand, the legitimacy of physical claims depends on our capacity to deal with the approximations rendered necessary by the shortcomings inherent in judgments of reality. On the other hand, the existence of such a function is itself justified from a transcendental viewpoint and it is explained, so to speak, bottom-up from the consideration of the empirical observations, to which this function must conform. In other words, mathematical judgments, according to Reichenbach — and differently from Cassirer, as we shall see in the next subsection - although being synthetic a priori, acquire a meaning for cognition only insofar as they are consistently applied to reality. Above all, the role of mathematical syntheses appears somewhat secondary to the "imposition" determined by experience on the choice of the mathematical structures that are supposed to represent it.

To a certain extent, what Reichenbach is considering here is a two-step "constructional" interpretation, in which the two levels, the set of formal assumptions and the set of empirical (approximated) data, cooperate in order to form a solid ground for scientific knowledge. ${ }^{12}$ An echo of this issue will be clearly reverberating in the idea of the mutuality of the coordination, a central element of his 1920 formulation to which we shall return below. Let us first consider the impact of Cassirer's conception of Zuordnung on Reichenbach's thought.

\subsection{Cassirer's Influence}

After the scientific - especially mathematical-developments of the nineteenth century, critical philosophy was confronted with a different form of objectivity. ${ }^{13}$ In a paper of 1907, "Kant und die moderne Mathematik," and more extensively in the volume Substance and Function of 1910, Cassirer set out to clarify the 
new task of critical inquiry, that of accounting for the lately transformed manner of concept formation (Begriffsbildung), and providing a new logic of objective knowledge.

In his 1910 monograph Cassirer, starting from an analysis of the evolution of modern mathematical natural sciences, and inspired by the new logicist currents in the foundations of mathematics, proposed a theory of the concept built on purely formal notions of function, series and order (or order system). Intuition, downplayed in favour of concept, takes part in the process of knowledge only once it is unified by pure thought. This unification can be understood as a subsumption under a system of relations and functional dependencies that is similar to the mathematical construction of concepts and series, and ordered accordingly. Each element of the series is constituted by the relation it bears to the other members of the series to which it is coordinated, while, at the same time, each is meaningfully correlated to members of other series. This network of dependencies and functional relations is grounded on this peculiar notion of coordination as constitutive of objects. ${ }^{14}$

Cassirer interpreted the historical development of mathematics and the mathematical sciences of nature according to a "genetic" conception of knowledge, as a generative progression of abstract structures (or "order systems") converging towards a merely regulative ideal: the achievement of rational completeness of the conditions for the possibility of experience. ${ }^{15}$ In this framework, critical philosophy becomes a "universal invariant theory of experience," for it ideally aims at identifying the ultimate logical invariants (the real a priori) "which lie at the basis of any determination of a connection according to natural law." "I In the transition towards new stages of knowledge, Cassirer clarifies,

it is the "functional form" itself, that changes into another; but this transition never means that the fundamental form absolutely disappears, and another absolutely new form arises in its place. The new form must contain the answer to questions, proposed within the older form; this one feature establishes a logical connection between them, and points to a common forum of judgment, to which both are subjected. The transformation must leave a certain body of principles unaffected; for it is undertaken merely for the sake of preserving this body of principles, and these reveal its real goal. Since we never compare the system of hypotheses in itself with the naked facts in themselves, but always can only oppose one hypothetical system of principles to another more inclusive, more radical system, we need for this progressive comparison an ultimate constant standard of measurement of supreme principles of experience in general. [...] The goal of critical analysis would be reached, if we succeeded in isolating 
in this way the ultimate common element of all possible forms of scientific experience, i.e., if we succeeded in conceptually defining those moments, which persist in the advance from theory to theory because they are the conditions of any theory. At no given stage of knowledge can this goal be perfectly achieved; nevertheless it remains as a demand, and prescribes a fixed direction to the continuous unfolding and evolution of the system of experience. [Cassirer (1910/1923), 268-269]

In Cassirer's early works, a pivotal position is assigned to mathematics for its specificity in exhibiting the very fundamental intellectual syntheses on which sciences rest, as displayed by their historical succession. Thus, mathematical concepts have a crucial philosophical significance in that they allow for a lawful ordering of phenomena, and for assigning them objective meaning. This fact assumes an even deeper importance once it is made clear that the critique of knowledge takes off precisely where mathematical reasoning stops, namely by elucidating the role that mathematical concepts play in constructing our "objectual" reality ("gegenständliche" Wirklichkeit). ${ }^{17}$

Reichenbach openly builds on Cassirer's general approach in Substance and Function, where the most distinctive feature of scientific thought is that of proceeding according to a scheme of progressive dissolution of the concept of substance into that of function. As we have seen, for Cassirer the role of functions is that of constituting the objects of scientific representation through the connecting relation provided by the laws - a relation due to which each thing is mutually connected to every other. Reichenbach's probability function plays a similar role in the representation of reality for it enables the connection that is described by the laws of nature. Further, following Cassirer, Reichenbach places an emphasis on the essential function performed by certain theoretic components (the constants) within and relative to a specific construction-constitutive elements that will become simple variables in the successive stage of scientific evolution. ${ }^{18}$ As he explains,

[e]very constant is presented as a function; the natural constant which is simply given for certain laws and to whose measurement several experiments are dedicated is brought into connection with completely different quantities, so that it appears as a function whose specific value in the previous laws is only attained under special circumstances. [...] This is the general approach of physics: to resolve constants into functions, to find more general laws that contain the previous law as a special case. No end of this process is in sight. [Reichenbach (1916/2008), 115] 
Along with Cassirer and the Marburg tradition, Reichenbach's doctoral thesis takes as a starting point science in its actuality and regressively tries to reconstruct its conditions of possibility, in line with the transcendental method presented in Kant's Prolegomena. It is this same idea that will be at the core of Reichenbach's wissenschaftsanalytische Methode, the inductive method of logical analysis of science that he will more fully elaborate in his "Habilitation" thesis. ${ }^{19}$ This method should implement the identification of the actual principles presupposed by empirical sciences. It essentially represents the tool for detecting contradictions when comparing sets of coordinating principles (with their corresponding laws of nature) belonging to two different systems, one of which has developed from the other. Reichenbach will show the inconsistency of the Kantian System with the Einsteinian one precisely making use of this regressive approach.

Most interestingly, in his "Habilitation" thesis these remodeled Cassirerian elements cooperate to shape a crucial, explanatory strategy that appears under the name of "procedure of the continuous expansion" (Verfahren der stetigen Erweiterung) ${ }^{20}$ The idea is that the inclusion of the old theory into the new one occurs as a generalisation of certain principles of knowledge-more specifically, coordinating principles constituting the actual concept of knowledge- that have become inconsistent with the old system. Contradictions can emerge and a generalisation (or extension) of a determinate system can also be obtained within the system itself, by virtue of this specific procedure. As he elucidates in 1920,

[t]he contradiction that arises if experiences are made with the old coordinating principle by means of which a new coordinating principle is to be proved disappears on one condition: if the old principle can be regarded as an approximation [Näherung] for certain simple cases. Since all experiences are merely approximate laws [Näherungsgesetze], they may be established by means of the old principles; this method does not exclude the possibility that the totality of experiences inductively confirms a more general principle. It is logically admissible and technically possible to discover inductively new coordinating principles that represent a successive approximation of the principles used until now. We can call such a generalization "successive" [stetig] because for certain approximately realised cases the new principle is to converge toward the old principle with an exactness corresponding to the approximation of these cases. We shall call this inductive procedure the method of successive approximations [Verfahren der stetigen Erweiterung]. [Reichenbach (1920/1965), 68-69]

These are all motifs that Reichenbach inherited from Cassirer, although deprived of the regulative, ideal dimension in which they were embedded. Inciden- 
tally, this is a decisive element in Reichenbach's 1920 book, for the absence of this dimension could well imply a move towards realism. In fact, in an account of a progressive generalisation of principles, there are two possible directions to take: either take a stance towards a form of dynamical idealism, as is the case of Cassirer (and somewhat of the 1920 Reichenbach), or take a step towards realism, a position that Reichenbach will explicitly embrace for the first time in "Metaphysics and Natural Science" (1925a). The roots of this shift can be seen in the nuanced difference that there is between Reichenbach and Cassirer in assigning or not assigning a regulative meaning to the approximated generalisation of principles in the progress of science.

Thus, it is clear that Reichenbach intends his early interpretation of Zuordnung to stay in line with that of his teacher. ${ }^{21}$ Nonetheless, in Reichenbach's doctoral thesis the direction of the coordination is not only that of taking the mathematical structures and casting them onto the empirical material, almost assigning, as it were, the order from above, as it appears in Cassirer's work. As I mentioned above, in Reichenbach's interpretation the empirical sphere plays the crucial role of imposing the range of possible values and "controlling" the adequacy of the function through the given empirical frequency observed in the single case, and from there applied to the class which it belongs to. To accentuate the interesting difference with respect to the Kant-Cassirerian tradition Reichenbach intends to adhere to, let us recall that in Cassirer's paper of 1907 the mathematical syntheses provide the ground for using the physical ones. Mathematics, there, grants the lawfulness of physics, whereas here it is the physical considerations themselves that select and warrant that a certain mathematical structure is applicable to reality. This takes place only by accepting (pace Kant) the constitutively imperfect character of the coordination of the mathematical sphere to the physical one. In other words, although Reichenbach does not extend this discussion further, the relations of primacy are the reverse in the two accounts. We shall soon see how this idea will be fruitfully strengthened in his 1920 monograph.

\section{Elements of a Revised "Kantian" Proposal}

\subsection{Mathematical vs. Physical Coordination}

The declared aim of The Theory of Relativity and A Priori Knowledge is the revision of the Kantian doctrine of the a priori in light of the theory of relativity. Along the same direction undertaken in the doctoral thesis, Reichenbach elaborates further on the issue of coordination, but now integrating Hilbert's axiomatic model. ${ }^{22}$ In set theoretic language, he explains that the difference between mathematical and physical coordination depends on the difference between the mathematical 
and the physical types of concept. The former is "univocally determined by the axioms and definitions of mathematics," i.e., it is implicitly defined through its relation to the other mathematical concepts so that it "receives meaning and content within the framework of definitions." ${ }^{23}$ Definitions, in fact, indicate how a term is to be related to the others, whereas the rules according to which concepts are defined are given by axioms. The latter, however, cannot be determined by axioms and definitions. Whatever system of mathematical equations we may create and use to represent physical events, it will lack a fundamental statement, that is, the assertion concerning the validity of that system for reality.

This fact implies a decisive asymmetry in the two types of coordination, precisely as Reichenbach underlined in his (1916). But in the 1920 account, there is a new element that he acquires after reading Schlick's General Theory of Knowledge (1918): the concept of univocality (Eindeutigkeit). In the mathematical coordination both coordinated sets are wholly and univocally (eindeutig) determined in their terms and internal order. According to Reichenbach, the peculiarity of the coordination carried out in the cognitive process is that, when the set of well defined fundamental equations of physics is coordinated to the empirical matter, we have to face the very fact that one side of this coordination is not defined; neither can we define the direction of the coordination. As Reichenbach makes clear,

the defined side does not carry its justification within itself; its structure is determined from outside. Although there is a coordination to undefined elements, it is restricted, not arbitrary. ${ }^{24}$ This restriction is called "the determination of knowledge by experience." We notice the strange fact that it is the defined side that determines the individual things of the undefined side, and that, vice versa, it is the undefined side that prescribes the order of the defined side. The existence of reality is expressed in this mutuality of coordination. [Reichenbach (1920/1965), 42]

Similarly to that of mathematical coordination, a criterion of univocality for physical coordination is introduced. We can deem a physical theory true when it leads to a consistent coordination, that is, when the coordination is univocal (or empirically confirmed). To characterise cognitive coordination as univocal means indeed that "a physical variable of state is represented by the same value resulting from different empirical data." In this account, perceptions provide the required criterion. $^{25}$ Furthermore, univocality is also essential for the consideration of a system of principles as a whole when compared to reality, as we shall see below.

The revised critical question now becomes: what principles allow for univocality? Reichenbach's answer is that Kant's system can be modified and made compatible with the evolution of science only by changing his doctrine of the a 
priori and by determining which principles of the coordination are the new ones, and what their new function is.

\subsection{Two Meanings of A Priori and the Distinction between Ax- ioms of Coordination and Axioms of Connection}

As is well known, in The Theory of Relativity and A Priori Knowledge Reichenbach proposes an interesting version of the a priori-the so-called "relativized a priori" 26 - that he views as divided according to its two components: "First it means 'necessarily true' or 'true for all times,' and secondly, 'constituting the concept of object.",27

Although the theory of relativity has shown the indefensibility of the first component, in 1920 Reichenbach still supported the second form of synthetic a priori as a constitutive element of knowledge in general, but revisable according to the evolution of science. Thus, again following an idea expressed by Cassirer, Reichenbach emphasised that "a priori" means "before knowledge," but not "for all time" and not "independent of experience." 28 Hence, he gave an interpretation of the cognitive coordination as based on contingent, coordinating principles that we need to presuppose in order to form, or constitute univocally, the objects of (scientific) knowledge-more specifically, in this case, the objects of physics. All these principles (including probability and causality) are constitutive a priori, yet nevertheless fallible, and theory-specific.

One of the most interesting features of this little but very rich monograph is the repetition and re-elaboration of the distinction between the principle of the lawful distribution (probability) and the principle of the lawful connection (causality), which Reichenbach introduced in his doctoral thesis. Now this differentiation is presented in the form of a distinction between certain principles of knowledge called the axioms of coordination (Zuordnungsaxiome) and the axioms of connection (Verknüpfungsaxiome), where only the first ones are truly constitutive, even though contingently. ${ }^{29}$

In 1920, Reichenbach sketched an axiomatic conception of physics by stating a sharp distinction between these two types of axioms-a distinction that will later fall victim to his crucial shift from (constitutive) principles of coordination to (conventional) coordinative definitions. This shift followed a famous exchange with Moritz Schlick in autumn 1920, at the end of which Reichenbach was urged to accept the conventional nature of his constitutive principles. ${ }^{30}$

The axioms of connection are the empirical laws of physics, the fundamental equations of a theory. Reichenbach gets the term "Verknüpfungsaxiome", which can be traced back to Hilbert's Grundlagen der Geometrie, from the interpretation presented in an article by Arthur Haas (1919). ${ }^{31}$ There, Haas describes the history 
of the physical axiomatisation as an evolution in the direction of a more unitary image of nature, that is, an evolution in terms of a wider connection (Verknüpfung) created by the laws within different fields. In this respect, formulating new physical laws means disclosing previously unseen connections. ${ }^{32}$ Consequently, Reichenbach considers the axioms of connection as empirical laws in the usual sense, involving already sufficiently well defined concepts. Yet, as we have seen, the concepts in such equations require further qualification, viz., the assertion that they are valid for reality. It is only through the axioms of coordination that how these concepts can de facto apply to reality can be shown. And that is precisely their role: providing a "physical" definition of the concepts occurring within the axioms of connection. In that sense, the former determine the meaning of the latter and they are therefore constitutive of the concept of the physical object. Thus, the axioms of coordination determine the rule of the application of the axioms of connection to reality, that is, they determine the rules of the connection.

Finally the axioms of coordination are required in order to state the univocal coordination of these concepts to reality. In Reichenbach's words:

Although [the coordinating principles] are prescriptions for the conceptual side of the coordination and may precede it as axioms of coordination, they differ from those principles generally called axioms of physics. The individual laws of physics can be combined into a deductive system so that all of them appear as consequences of a small number of fundamental equations. These fundamental equations still contain special mathematical operations; thus Einstein's equations of gravitation indicate the special mathematical relation of the physical variable $R_{i k}$ to the physical variables $T_{i k}$ and $g_{i k}$. We shall call them, therefore, axioms of connection. The axioms of coordination differ from them in that they do not connect certain variables of state with others but contain general rules according to which connections take place. In the equations of gravitation, the axioms of arithmetic are presupposed as rules of connection and are therefore coordinating principles of physics. [Reichenbach (1920/1965), 54]

Additionally, they must also be of such kind that they make the coordination univocal. Even if there are arbitrary elements in the principles of knowledge, their combination is no longer arbitrary. This is a crucial point, Reichenbach maintains, that had not been sufficiently accounted for by the conventionalists. ${ }^{33}$

Having said all this, however, the question remains whether among the axioms of coordination there are some that are more significant, or, to put it differently, whether there are principles that are "more constitutive" than others.

Coordinating principles refer to the conceptual side of the coordination, and are purported to define what is real. Reichenbach indicates a non-exhaustive list 
of principles, like time and space, because they allow for the definition of a single real point by means of four numbers. ${ }^{34}$ Other important axioms of coordination are the principle of genidentity (or identity over time) and the principle of probability. This last principle is the variant of the principle of the lawful distribution that we encountered above and that is relativized, being still constitutive but revisable. This principle now simply "defines when a class of measured values is to be regarded as pertaining to the same constant." 35 The other principle is one that occurs for the first time in Reichenbach's writings, with an expression, genidentity, that was officially coined by the gestalt psychologist Kurt Lewin in 1922. ${ }^{36}$ Of this principle Reichenbach only says that it indicates how physical concepts have to be connected in sequences in order to define "the same thing remaining identical with itself in time." ${ }^{37}$ For example,

[w]hen we speak of the path of an electron, we must think of the electron as a thing remaining identical with itself; that is, we must make use of the principle of genidentity as a constitutive category. This connection between the conceptual category and the experience of coordination remains an ultimate, not as an analysable residue [nicht analysierbarer Rest]. But this connection clearly defines a class of principles that precede the most general laws of connection as presuppositions of knowledge though they hold as conceptual formulas only for the conceptual side of the coordination. These principles are so important because they define the otherwise completely undefined problem of the cognitive coordination. [Reichenbach (1920/1965), $55]$

What is striking in this account of the coordinating principles is the fact that even though Reichenbach does not provide a detailed account of all these axioms, he does not seem to assign them the same significance. These last two principles in particular hold a pivotal position and play a more fundamental role with respect to the other coordinating axioms. Probability and genidentity are both indeed required by all other coordinating axioms that we use to assign content to the concepts occurring in the connecting axioms. The values appearing within the equations receive their physical meaning by virtue of the coordinating axioms, but the act of measuring itself is primarily dependent upon the principle of probability, as well as, more generally, on the principle of genidentity. These two constitutive axioms are, so to speak, meta-axioms of coordination: they are constitutive of the constitutive axioms, in that they represent an essentially underlying level of constitutivity, as I will argue more in detail in 4.1.

The distinction between connecting and coordinating axioms has been understandably regarded as a very striking version of the relativized a priori. ${ }^{38} \mathrm{In}$ 
The Theory of Relativity and A Priori Knowledge, this distinction serves well as a foundation for the outline of a model of scientific change, that is, of the evolutionary transformation in the concept of knowledge and the consequent shift in the logical conditions presupposed by the new object of physical knowledge. To illustrate how the advance from theory to theory takes place in light of these two types of axioms, Reichenbach uses the example of the metric. In Newtonian physics, he explains, the Euclidean metric was a coordinative axiom because it determined "the relations according to which space points combine to form extended structures independently of their physical quality." In Einstein's physics, on the contrary, the metric becomes a function of the totality of other surrounding bodies. Thus, Reichenbach concludes, "the metric is no longer an axiom of coordination but has become an axiom of connection." 39

\section{Further Developments in 1920}

\subsection{Coordinating Properties, Not Just Structures}

The distinction between axioms is a key element in the framework of this monograph, but unfortunately Reichenbach does not go into it more thoroughly. To be sure, The Theory of Relativity and A Priori Knowledge was conceived and written in only a few days in the spring of $1920 .{ }^{40}$ The manuscript, entirely available at the Pittsburgh Archives, was ready for publication, with minor modifications, during the summer of 1920. This material makes it clear that the distinction between axioms in these terms was inserted only later in revisions. Interestingly, in the drafts of this work there are traces of another specification in a marginal note, added later but eventually omitted from the published version. With respect to the passage that I have quoted above, p. 12, in this note he writes:

The specific laws can be combined into a deductive system so that all of them appear as consequences of a few fundamental equations. We will call these equations axioms of connection because they express the connection between the specific physical magnitudes. Opposite to these are the axioms of coordination, which represent the properties of all bodies, reduced to a minimum of propositions. An example of coordinating axioms of old physics are the axioms of geometry; Maxwell's equations are an example of connecting axioms. [HR 026-03-01, 56 bis $]^{41}$

Now, the Zuordnungsaxiome represent the possibility that the general properties of all bodies be reduced to a minimum of propositions. Here, the coordinating axioms are in fact entitled to deal with the properties of bodies. The system of 
equations is the general framework in which the connection among real things is actually achieved. Or better, this system represent the more general framework into which things have to be cast if they have to be thought of as real. This is an interesting specification, for above all it does not primarily associate the coordination directly with the idea that we saw at play in the dissertation, that is, the idea of "merely" representing a bridge between the formal structures and the real ones.

Let's briefly summarise what we have seen so far. In the doctoral thesis, the coordination was carried out by means of the notion of approximation. Formal structures could describe physical structures only by way of a certain approximation. The principle of probability was the tool Reichenbach implemented in order to treat the issue of approximation in formal terms and thus fill the gap between the two structures.

In (1920), the situation is complicated by the fact that not only is a principle of probability required in the same sense of the doctoral thesis, but there are also several other principles of the coordination (i.e., application) of these mathematical structures that are not strictly speaking related to the principle of probability. Some of these principles are, for instance, the axioms of arithmetic, which are presupposed as rules of connection in the equations of gravitation, as well as in allowing for the representation of certain physical relations by means of mathematical objects. This is the case of physical forces that we identify as vectors, for instance. It must be emphasised, though, that even if a number of other axioms of coordination can be isolated within the scientific construction, they also necessarily presuppose the principle of probability at a higher level, as the ultimate principle of the effective representation of material objects in any formal (mathematical) expressions.

In my reading, probability is a meta-constitutive, coordinating axiom for it enables the other axioms of coordination to really perform the coordination of certain structures, like space and time, or the axioms of arithmetic, to real things (objects). Beside the principle of probability, the principle of genidentity also appears to be "more constitutive" than other constitutive principles. In fact, before deciding to coordinate whatever formal structure to the unformed reality in order to constitute the object, an evident requirement is that this object persists over time $a s$ the same object. The idea behind both principles is that each eventually supplies some very general tool for the conceptual identification that is called for when applying formal structures to reality. 


\subsection{Axioms of Connection, Axioms of Order and Axioms of Coordination}

Earlier I mentioned that in the original manuscript of The Theory of Relativity and A Priori Knowledge a distinction of axioms in terms of connection and coordination was introduced by Reichenbach only later in revisions. Moreover, among Reichenbach's manuscripts and various drafts for Axiomatik (1924), there is evidence of a later attempt to clarify and further elaborate on this question in an unpublished short paper entitled "Der Begriff des Apriori und seine Wandlung durch die Relativitätstheorie" (The Concept of A Priori and Its Transformation through Relativity Theory). ${ }^{42}$ There, Reichenbach returns to Hilbert's terminology of the Grundlagen, now distinguishing three different kinds of axioms: beside the previous two, he adds a third kind, the axioms of order (Axiome der Ordnung).

These axioms share exactly the same features with the axioms of coordination. They are both constitutive a priori in the revised Kantian sense of (1920), they are fallible (as is the distinction among axioms itself) and theory-specific. Unfortunately, this interesting distinction is only outlined in the paper, and Reichenbach does not expressly formulate the new axioms, but they clearly tend to be assimilated into the process of constituting a framework in which the representation of real things can in principle be embedded. However, these new axioms, which are placed between the connecting and the coordinating axioms, need to be supplemented by the axioms of coordination.

Let us follow Reichenbach's manuscript and start with the axioms of connection. They are again characterised in the same way we have seen so far, namely as special laws of physics. These axioms describe special relations, more specifically laws of experience (Erfahrungsgesetze). That is, they define individual things (Einzeldinge).

The axioms of coordination and of order do not define individual things, but rather determine more generally what the object (Gegenstand) is. For instance, "the probability function determines identity." This is to be understood in the same terms we have seen before, i.e., physical magnitudes can be represented by the same value resulting from different empirical data by virtue of the probability function. The constitutive axioms also specify the measurable relations of the objects that lead to the connection. In this, he continues, they constitute the physical, therefore measurable object. So it is right to say that the phenomena (Dinge qua Erscheinungen) conform to our thought. But this does not exclude the converse, namely that our thought is directed by them. That is why the special form of the coordinating and ordering axioms has to be modified when they no longer can ground the representation of our experience. ${ }^{43}$

In this manuscript, Reichenbach basically formulates a number of questions and sketches only a few answers. Despite the lack of a further elaboration, this 
text shows that the classical distinction in terms of coordinating and connecting axioms has to be construed differently from the way it is generally understood in the secondary literature. Interestingly, he asks: "How is cognition as coordination of fictitious magnitudes to reality possible? And how is the ordering of these magnitudes possible?" According to Reichenbach, only insofar as we make specific presuppositions about the coordination and the ordering can we define what an identical and real object is, and how it can be related to other things. Further,

What is a real law in this framework? A real law is what remains invariant under coordinate transformations. What does measurability mean? Measurability means to assign an arbitrary order within the coordinates. A real thing is what appears in such laws as magnitude and that is measured according to these laws. [HR 024-15-02] ${ }^{44}$

Thus, there are two layers of constitutivity to be differentiated. Accordingly, the fundamental question regarding knowledge is to be answered on two levels. Cognition means, on the one hand, the coordination of certain fictitious magnitudes to reality and, on the other, the act of ordering these magnitudes within a specified structure. In the cognitive process, the real thing is what appears as magnitude within - and is measured according to-specific laws. But measuring requires a pre-constituted order. This order, in turn, acquires its meaning only by being coordinated to actual objects that can be identified according to certain ultimate principles. Therefore, in this unpublished manuscript, the cognitive component in the process of knowledge is deployed first by creating a determinate modality for ordering, and then by coordinating the ordered structure to actual things (or also, by extension, to events), i.e., things (or events) that can be recognised as that specific individual thing (or event).

In other words, here the Axiome der Zuordnung are concerned with stating what can be isolated and identified as the "real" to be ordered in the flux of perception. This ordering is possible only insofar as we have a framework in which the "real" can be inserted. This is not to be understood as the set of physical laws, but as the framework enabling these laws to be conceived. As in the example given in this manuscript, which Reichenbach also employed in (1920), space and time are not characterised by and within the laws of physics, but rather provide the framework in which it is in principle possible to identify real things with the addition of the laws of physics. In the same sense, the axioms of arithmetic referring to the vectors are presupposed when we treat the force as a mathematical vector.

But the final step in the coordination to reality is performed by way of another kind of coordinating principles. Before, I suggested that in the 1920 account there are two coordinating principles that appear to be more significant than others, 
namely the principle of genidentity and the principle of probability. These are clearly to be located at the level of the coordinating principles of the account that Reichenbach sketches on this occasion. The idea of the two-level co-ordination is confirmed by this manuscript, where the two constitutive moments are separated according to the two different functions they embody and serve in cognition.

\subsection{A Conventionalist Shift?}

After the correspondence with Schlick and his consequent "conventionalist shift", around the end of 1920, Reichenbach no longer talks about constitutive principles.

The first development of this discussion is apparent in a report that he delivered at the Deutsche Physikertag in Jena, in September 1921, on his plan to axiomatise relativity theory. ${ }^{45}$ The fundamental methodological innovation of this short paper is to present an axiomatisation in which the starting point consists of making use of axioms that can ideally make direct contact with empirical (or experimentally testable) facts, and of complementing them by introducing a number of coordinative definitions for the construction of the conceptual content of the theory. ${ }^{46}$

In his second monograph on relativity theory, the Axiomatik (1924), Reichenbach emphasises the importance of this novel approach, that it makes a clear-cut separation between the conventional component (the coordinative definitions) and the empirical, factual one (the empirical axioms). In fact, the axiomatisation has to be primarily based on observable facts, and it is only from these facts that the abstract conceptualisation will derive. For this approach Reichenbach now coins the expression "constructive axiomatisation", ${ }^{47}$ a clear development of the regressive method - the wissenschaftsanalytische Methode - defined in (1920).

Despite the sharp distinction between definitions and axioms, in the Axiomatik, the principle of probability, in the form of the principle of induction (or of inductive simplicity), nevertheless finds a peculiar position under the general name of "epistemological principles", i.e., principles presupposed by any factual statements:

One of [these principles] is the assumption that the experiment, if subsequently repeated, will always yield the same result, the assumption of causality. Furthermore, the principle of induction is presupposed; for instance, certain values of measurement will be connected by a simple curve and this curve will be called an empirical law. [Reichenbach (1924/1969), 5]

As is well known, all these issues will maintain a focal position in Reichenbach's philosophical system. Let me just recall that as far as the principle of 
genidentity is concerned, Reichenbach no longer mentions it in his (1924). However, this principle is in the background of his causal theory of time, even though Reichenbach will explicitly re-acknowledge its importance only in The Philosophy of Space and Time (1928). There, he describes it as a very deep principle of our natural knowledge (ein sehr tiefes Prinzip der Naturerkenntnis), an empirical but absolutely essential principle of time order. ${ }^{48}$ What is meant by simply claiming that genidentity is an empirical principle is not really clear. Neither does Reichenbach seem to solve the issue in his posthumous The Direction of Time (1956), where this principle still plays a crucial, and actually constitutive, role. But I shall leave this discussion for another occasion.

To return to the question of Reichenbach's shift towards conventionalism, now we can ask: to what sorts of assertion is this shift to be applied? Let us take the classic example of the coordinative definition represented by the concept of length unit elaborated in his 1924 axiomatisation. This concept is a mathematical one, and it states that "a certain particular interval is to serve as [standard of] comparison for other intervals." The physical definition, to the contrary, needs to be able to project, as it were, the mathematical concept onto the unformed reality. But being coordinative, and thus conventional, such a definition is also arbitrary. In our example, it is represented by the designator of the Paris standard meter as the unit of length. This definition clearly presupposes the mathematical one. Therefore, he continues, physical (or coordinative) definitions are kinds of real definitions that coordinate a mathematical definition to a "piece of reality." Since the coordination must be univocal, the necessary requirements for this purpose are given by the axioms. ${ }^{49}$

According to what we have seen above, we can regard the axioms of order of the unpublished manuscript as the coordinative definitions of the constructive axiomatisation. The main feature that Reichenbach assigns them in that paper is that they determine the measurable relations that lead to the connection (that is, to a possible empirical law). Reichenbach also adds that measurability means to attribute an arbitrary order within the coordinates. Already in The Theory of Relativity and A Priori Knowledge, Reichenbach refers to the classical example of the length of a physical rod as "defined by a large number of physical equations that are interpreted as 'length' with the help of readings on geodetic instruments." 50

To conclude, in (1920) there are clearly coordinating principles that are, as it were, constitutive of the constitutive principles. These cannot be turned into conventions, as is the case of probability. Although the spirit of Reichenbach's constructive axiomatisation is oriented towards a conventionalist stance, the conventions only apply so far as a theory-specific package is concerned. In fact, his alleged conventionalist shift concerns only the Axiome der Ordnung, but not all constitutive axioms. 


\section{Relativizing the Relativized A Priori}

What consequences can be drawn from this new reading? If my interpretation of the two-level constitutive account of Reichenbach's principles of knowledge is correct, the relativized a priori needs to be relativized in turn. In Reichenbach's model, the constitutive order axioms can be turned into coordinative definitions (still holding an a priori status), whereas other (meta)-constitutive coordinating principles, such as probability and genidentity, are relativized, or even "absolutised", and turned into different assumptions in his later works. Although an attempt to provide a firmer axiomatic footing to the set of principles of knowledge is inscribed in Reichenbach's empiricist tendency, he will not be able to do away with these two assumptions. He will try to provide a different kind of justification for probability, but he will uncritically assume genidentity simply based on the motivation that things would not be conceivable otherwise.

This is not the place to start a discussion on the possible implications of a twolevel account of the constitutive, relativized a priori, but this tripartite distinction among axioms could be helpful in developing a more structured framework. As in Reichenbach's account, a double layer of a priori could be envisaged, namely a set of more fundamental constitutive principles that should appear to be valid for scientific objects at the most general level, together with some subsets of other constitutive principles, which would themselves depend in turn on the most fundamental ones. These subsets would be specific to and would function in the special sciences they would have to be applied to. In conjunction with these, other sub-subsets of connecting axioms could be thought of in terms of individual laws pertaining to each specific domain of science.

The current debate over the possibility of maintaining some form of constitutive principles in the early Reichenbachian fashion should benefit from this lesson, and should, moreover, take account of the fact that the constitutive principles are not only different among themselves horizontally, or from a qualitative point of view, but should also be structured within themselves, as it were, vertically.

\section{Acknowledgements}

Special thanks goes to the Pittsburgh Centre for Philosophy of Science, which hosted me during the academic year 2008-2009, and to the group of visiting fellows for valuable comments on a previous draft of this paper, in particular to Claus Beisbart, Chris Pincock and Erik Curiel. Research for this paper was supported by a grant of the Swiss National Science Foundation. I also wish to thank the Directors of the Archives of Scientific Philosophy in Pittsburgh and Konstanz for their permission to quote from the Hans Reichenbach Collection. I am especially 
grateful to Brigitte Parakenings from the Konstanz Archives for her valuable help in finding and supplying unpublished material. All rights are reserved.

\section{Notes}

${ }^{1}$ Cf. Reichenbach (1935), (1936b) and (1937).

${ }^{2} \mathrm{Cf}$. Reichenbach's address in the section on logical empiricism at the famous Paris Congress of 1935, (1936a), as well as his (1936c).

${ }^{3}$ Reichenbach (1920). This text was presented by Reichenbach as "Habilitationsschrift" to obtain the qualification for university teaching under the formal supervision of Erich Regener, physics professor at the "Technische Hochschule" of Stuttgart.

${ }^{4}$ Reichenbach was one of the first five students attending Einstein's lectures on general and special relativity, and on statistical mechanics in Berlin, between 1917 and 1920. His notebooks, like all the original material from the Hans Reichenbach Collection (HR) that I will quote in the next sections, are available at the Pittsburgh Archives of Scientific Philosophy, and they can be found in the folder HR 028-01-01/05.

${ }^{5}$ Reichenbach (1916).

${ }^{6}$ For a synopsis of Reichenbach's dissertation, see Eberhardt's "Reliability via Synthetic A Priori - Reichenbach's Doctoral Thesis on Probability", in this same volume.

${ }^{7}$ Here, I only deal with the way these two principles interact in the process of cognitive coordination, not much with the question of their foundation. In particular, as far as the principle of probability is concerned, Reichenbach provides a justification that he reckons to be in line with the one Kant employed for the principle of causality, that is, a "transcendental deduction". Cf. Reichenbach (1916/2008), $105 \mathrm{ff}$.

${ }^{8}$ Reichenbach (1916/2008), 125-129.

${ }^{9}$ For more details on these issues see again Eberhardt's contribution to this volume.

${ }^{10}$ There are several elements that would suggest that the principle of probability, as Reichenbach formulated it in 1915, cannot simply be placed beside that of causality. There, probability plays in fact a dual role: as a synthetic a priori principle, it serves to capture specific features of reality that cannot be subsumed under the principle of causality, and to give their representation for the subject; yet, the principle of probability is not only important from an "ontological" point of view, but also from a more methodological one. On the one hand, the principle of probability appears to be formulated in "causal" terms, namely in the treatment of causally dependent and independent trials. On the other hand, probability is the most fundamental tool allowing each natural science to account for real events, and in this very sense it is presupposed by causality itself, making it ultimately rely on probability.

${ }^{11}$ Despite Reichenbach's Kantian terminology, in his work there is a tension in relation to the Kantian system: the principle of probability seems to suggest the statistical character of the laws of nature, and this would implicitly mean discarding the deterministic idea that is behind Kant's fundamental principle of causality. This is in fact the direction that Reichenbach will take-with some vacillation - after the publication of his doctoral thesis. This tension in Reichenbach's originally "Kantian" intentions has been already emphasised by Milic Čapek long ago. As he remarked, "from [Kant's] point of view, it is meaningless to claim that empirical reality is "rationally inexhaustible" and that the mathematical structure fits the observed data only loosely. [...] [T]o postulate a special a priori status for the principle of statistical distribution, as Reichenbach did, was thoroughly un-Kantian.” Čapek (1958), 88-90. 
${ }^{12}$ As Reichenbach makes clear, "it is precisely the task of experience to establish which are the important influences and which others may be neglected. Naturally, this experience can only be obtained by measurements; they establish whether the theoretically calculated numbers are anywhere close to the numbers occurring in reality. [...] Hence, physical experience consists in the establishment of a numerical approximation by experiment, and conversely the physical principle assures by virtue of experience the approximate validity of certain numbers for a class of natural events." Reichenbach (1916/2008), 123-125.

${ }^{13}$ See Richardson (1998), ch. 5, and Ryckman (1991).

${ }^{14}$ Cf. Ryckman (1991), $61 \mathrm{ff}$.

${ }^{15}$ On all these issues, see Friedman (2005), $72 \mathrm{ff}$.

${ }^{16}$ Cassirer (1910/1923), 269.

${ }^{17}$ In Cassirer's words: "Erst wenn wir begriffen haben, dass dieselben Grundsynthesen, auf denen Logik und Mathematik beruhren, auch den wissenschaftlichen Aufbau der Erfahrungserkenntnis beherrschen, dass erst sie es uns ermöglichen, von einer festen gesetzlichen Ordnung unter Erscheinungen und somit von ihrer gegenständlichen Bedeutung zu sprechen. Erst dann ist die wahre Rechtfertigung der Prinzipien erreicht." Cassirer (1907), 44-45.

${ }^{18}$ Cf. Cassirer (1910/1923), $265 \mathrm{ff}$.

${ }^{19}$ And indeed, Reichenbach acknowledged the common approach in both writings, as he underlines in his (1920/1965), 75: "The author was able to carry through such an analysis for a special domain of physics, for the theory of probability. It led to the discovery of an axiom that has fundamental significance for our understanding of physics, and as a principle of distribution finds its place next to causality, a principle of connection."

${ }^{20}$ The English edition quite freely translates it with "method of successive approximations."

${ }^{21}$ Reichenbach attended Cassirer's lectures on German idealism in the winter semester 19131914, while he was enrolled at the University of Berlin. In the bibliographic references to his (1916), Reichenbach only mentions Cassirer (1910), so it is not clear whether he was familiar also with his (1907).

${ }^{22}$ This is an element that comes into his account after studying Schlick (1918).

${ }^{23}$ Reichenbach (1920/1965), 34-35.

${ }^{24}$ That there is a limit to the arbitrariness of physical coordination is a crucial point that Reichenbach will keep emphasising also later, to characterise his account with respect to the conventionalists'. See especially his correspondence with Schlick, which I mention below, footnote 3.2.

${ }^{25}$ Reichenbach (1920/1965), 44.

${ }^{26}$ To be sure, this expression was coined by Michael Friedman. Cf. his (1999), ch. 3, and references therein.

${ }^{27}$ Reichenbach (1920/1965), 48.

${ }^{28}$ Reichenbach (1920/1965), 48. Cf. Cassirer (1910/1923), 269: “A cognition is called a priori not in any sense as if it were prior to experience, but because and in so far as it is contained as a necessary premise in every valid judgment concerning facts." [emphasis in the original] As Ryckman notices, "with this modication, the way is open towards viewing, as do Poincaré, Schlick, Einstein and Reichenbach, conventions as having the logical status of a priori elements." Ryckman (1991), 85.

${ }^{29}$ Incidentally, some features assigned to causality in the dissertation are now integrated into the notion of probability, as we shall see, for instance, below at p. 18. As I briefly indicated in footnote 2.1, in Reichenbach's writings of the late 1920s, and especially in those of the 1930s, probability, instead of completing the principle of causality, will end up simply founding it, and causality will be expressed in probabilistic terms, like in (1925b) — this in opposition to the approach displayed 
in the dissertation, where probability was first defined on the basis of causally dependent and independent trials.

${ }^{30}$ This exchange consists of five letters, in the order: HR 015-63-23, Schlick to Reichenbach, 25 September 1920; Reichenbach to Schlick, 17 October 1920 (in the Schlick Collection at the Wiener Kreis Stichting, Amsterdam); HR 015-63-22, Schlick to Reichenbach, 26 November 1920; HR 015-63-20, Reichenbach to Schlick, 29 November 1920; HR 015-63-19, Schlick to Reichenbach, 11 December 1920. This correspondence has been largely referred to and analysed in the secondary literature. Just to mention a few, see Coffa (1991), 201-206; Hentschel (1990), 507 ff.; Friedman (1999), 62-65; Ryckman (2005), 51 ff. Further, this exchange is also mentioned by Schlick in his (1921) and by Reichenbach in his (1922a). All these letters are now entirely available at http://echo.mpiwg-berlin.mpg.de/content/modernphysics/reichenbach1920-22.

${ }^{31}$ The paper was emblematically entitled "Die Axiomatik der modernen Physik" —an idea that the young Reichenbach certainly found fascinating.

${ }^{32}$ In his paper, Haas presents a survey of the axioms of physics (i.e., the axioms of connection) that he reckons complete. But although Reichenbach welcomes this classification, in footnote 15 to p. 54 he criticises Haas for not seeing the necessity of introducing physical axioms of coordination. Cf. Reichenbach (1920/1965), 111.

${ }^{33}$ See also above, footnote 3.1 .

${ }^{34}$ Reichenbach (1920/1965), 53.

${ }^{35}$ Reichenbach (1920/1965), 54-55.

${ }^{36}$ Lewin (1922).

${ }^{37}$ This principle will play an important part in both his (1928) and (1956). See below, p. 18.

${ }^{38}$ Friedman (1999), $60 \mathrm{ff}$.

${ }^{39}$ Reichenbach (1920/1965), 100. See Friedman (1999), 66, for his reading of Reichenbach's account of theory change according to this scheme. Friedman's own account of mathematicalphysical theories has a tripartite structure (a mathematical, a mechanical and a proper physicalempirical part) and is partly shaped by Reichenbach's. See his (2001), 79-80.

${ }^{40} \mathrm{Cf}$. his autobiographical notes of October 1927, HR 044-06-23.

41 "Man kann die Einzelgesetze unter sich in ein deduktives System bringen, sodass sie alle als Folgerungen einiger weniger Grundgleichungen erscheinen. Wir wollen diese, da sie die Verknüpfung der einzelnen physikalischen Grössen angeben, als Verknüpfungsaxiome bezeichnen; wir stellen sie zu den Zuordnungsaxiomen gegenüber, welche die allgemeinen Eigenschaften aller Körper, auf ein Minimum von Sätzen reduziert, darstellen. Ein Beispiel für Zuordnungsaxiome der alten Physik sind die Axiome der Geometrie, für Verknüpfungsaxiome die Maxwellschen Gleichungen.” HR 026-03-01, 56 bis.

${ }^{42}$ HR 024-15-02.

${ }^{43}$ In his words: "Es gibt: Axiome der Zuordnung, der Ordnung, der Verknüpfung. Die V.[erknüpfungs]A.[xiome] sind die spez. Gesetze der Physik, z. B. $R_{i k}-\frac{1}{2} g_{i k} R=T_{i k}$. Sie geben nur die spez. Relationen, Erfahrungsgesetze. (Definieren die Einzeldinge). Die beiden ersten sind apriori. D.h. nichts zeitliches: es hat keinen Sinn zu sagen, dass sie sich nicht ändern. [...] Ihre spez. Form ist durch den Stand unserer Erfahrung bestimmt. [...] Aber: sie bestimmen welches der Gegenstand ist (W[ahrscheinlichkeits]f[un]kt[ion] bestimmt Identität), und welches die messbaren Relationen des Gegenstands sind, die zur Verknüpfung führen $\left(d s^{2}=\right)$. Sie konstituieren den physikalisch messbaren Gegenstand. Darum ist es richtig, dass sich die Dinge (d. Erscheinung) nach unserem Denken richten. Aber das schliesst die Umkehrung nicht aus: dass sich unser Denken nach den Dingen richtet. Vielmehr werden wir die spez. Form der Z.[uordnungs]A.[xiome] und O.[rdnungs]A.[xiome] ändern, sowie wir damit die Erfahrung nicht mehr darstellen können.” HR 024-15-02. 
44،"Frage: Wie ist die Erkenntnis als Zuordnung von fikt.[iven] Grössen zur Wirklichkeit und als Ordnung dieser Grössen möglich? Antwort: Nur dadurch, dass man bestimmte Vorauss.[etzungen] für die Zuordnung und die Ordnung macht, welche definieren, was ein identische[r], reale[r] Gegenstand ist und wie e[r] mit andern Dingen in Relation gebracht werden kann. [...] Die Relativitätstheorie hat gezeigt, dass apriore Sätze wandelbar sind. Aber sie hat das nicht in jener flachen Form vollzogen wie die Empiristen, die da sagen 'alles ist Erfahrung', sondern sie hat eine wirkliche Wandlung des Gegenstandsbegriffes vollzogen. Reales Gesetz ist das, was invariant ist gegen $\operatorname{Tr}$ [ansformation] d. Koord[inaten]. Messbarkeit heisst beliebige Ordnung innerhalb d. Koord[inaten]. Wirkliches Ding ist das, was in solchen Gesetzen als Grösse auftritt u. nach solchen Gesetzen gemessen wird." HR 024-15-02.

${ }^{45}$ Reichenbach (1921).

${ }^{46}$ Reichenbach (1921/2006), 45.

${ }^{47}$ As he elucidates, "the constructive axiomatisation is more in line with physics than is a deductive one, because it serves to carry out the primary aim of physics, the description of the physical world.” Reichenbach (1924/1969), 5.

${ }^{48}$ As he explains in 1928 , this principle "enables us to speak of a unique time order and a unique now-point. Furthermore, it makes possible the concept of the individual that remains identical during the passage of time. It is therefore the most important axiom regarding time order, and we realize to what an extent the familiar concept of time order is based on this characteristic of causality. Of course, this axiom is a result of experience [es ist klar, daß es sich in diesem Axiom um einen Erfahrungssatz handeln kann]." Reichenbach (1928/1958), 142-143.

${ }^{49}$ Or, as he writes, "are derived from the facts laid down by the axioms." Cf. Reichenbach (1969), 7-9.

${ }^{50}$ Reichenbach (1920/1965), 40.

\section{References}

[1] Čapek, M. (1958), Reichenbach's Early Kantianism. Philosophy and Phenomenological Research, 19(1):86-94.

[2] Cassirer, E. (1907), Kant und die moderne Mathematik. Kant-Studien, 12:149.

[3] Cassirer, E. (1910), Substanzbegriff und Funktionsbegriff. Untersuchungen über die Grundfragen der Erkenntniskritik. Berlin: Bruno Cassirer. Translated as Substance and Function. Chicago: Open Court, 1923.

[4] Cassirer, E. (1921), Zur Einstein'schen Relativitätstheorie. Erkenntnistheoretische Betrachtungen. Berlin: Bruno Cassirer. Translated as Einstein's Theory of Relativity. Chicago: Open Court, 1923.

[5] Coffa, J.A. (1991), The Semantic Tradition from Kant to Carnap: To the Vienna Station. Cambridge: Cambridge University Press.

[6] Friedman, M. (1999), Reconsidering Logical Positivism. Cambridge: Cambridge University Press. 
[7] Friedman, M. (2001), Dynamics of Reason. Stanford: CSLI Publications.

[8] Friedman, M. (2005), Ernst Cassirer and the Philosophy of Science. In Continental Philosophy of Science. G. Gutting (ed.), Oxford: Blackwell Publishing, 71-83.

[9] Haas, A. (1919), Die Axiomatik der modernen Physik. Die Naturwissenschaften, 7:744-750.

[10] Hentschel, K. (1990), Interpretationen und Fehlinterpretationen der speziellen und allgemeinen Relativitätstheorie durch Zeitgenossen Albert Einsteins. Basel-Boston-Berlin: Birkäuser.

[11] Lewin, K. (1922), Der Begriff der Genese in Physik, Biologie und Entwicklungsgeschichte. Berlin: Springer.

[12] Reichenbach, H. (1916), Der Begriff der Wahrscheinlichkeit für die mathematische Darstellung der Wirklichkeit. Leipzig: Barth. Translated as The Concept of Probability in the Mathematical Representation of Reality. Eberhardt, F. \& C. Glymour (eds.), Chicago-La Salle, Ill.: Open Court, 2008.

[13] Reichenbach, H. (1920), Relativitätstheorie und Erkenntnis apriori. Berlin: Springer. Translated as The Theory of Relativity and A Priori Knowledge. M. Reichenbach (ed.), Berkeley-Los Angeles: University of California Press, 1965.

[14] Reichenbach, H. (1921), Bericht über eine Axiomatik der Einsteinschen Raum-Zeit-Lehre. Physikalische Zeitschrift, 22:683-686. Engl. transl. in Reichenbach (2006), 45-55.

[15] Reichenbach, H. (1922a), Der gegenwärtige Stand der Relativitätsdiskussion. Logos, X:316-378. Engl. partial transl. in Reichenbach (1959), 1-45.

[16] Reichenbach, H. (1922b), La signification philosophique de la théorie de la relativité. Revue philosophique de la France et de l'Étranger, 94:5-61. Engl. transl. in Reichenbach (2006), 95-160.

[17] Reichenbach, H. (1924), Axiomatik der relativistischen Raum-Zeit-Lehre. Braunschweig: Fried. Vieweg \& Sohn. Translated as The Axiomatization of the Theory of Relativity. M. Reichenbach (ed.), Berkeley-Los Angeles: University of California Press, 1969.

[18] Reichenbach, H. (1925a), Metaphysik und Naturwissenschaft. Symposion, 1(2):158-176. Engl. transl. in Reichenbach (1978), Vol. I:283-297. 
[19] Reichenbach, H. (1925b), Die Kausalstruktur der Welt und der Unterschied von Vergangenheit und Zukunft. Sitzungsberichte der Bayerische Akademie der Wissenschaft, November: 1933-1975. Engl. transl. in Reichenbach (1978), Vol. II:81-119.

[20] Reichenbach, H. (1928), Philosophie der Raum-Zeit-Lehre. Berlin-Leipzig: De Gruyter. Translated as The Philosophy of Space and Time. Reichenbach, M. \& J. Freund (eds.), New York: Dover, 1958.

[21] Reichenbach, H. (1932), Axiomatik der Wahrscheinlichkeitsrechnung. Mathematische Zeitschrift, 34(4):568-619.

[22] Reichenbach, H. (1933), Die logischen Grundlagen des Wahrscheinlichkeitsbegriffs. Erkenntnis, 3(4/6):401-425.

[23] Reichenbach, H. (1935), Wahrscheinlichkeitslehre. Leiden: Sijthoff. Engl. revised ed. in Reichenbach (1949).

[24] Reichenbach, H. (1936a), L'empirisme logistique et la désagrégation de l'a priori. In Actes du Congrès international de philosophie scientifique, Paris, 1935. Vol I: Philosophie scientifique et empirisme logique. Paris: Hermann, 28-35.

[25] Reichenbach, H. (1936b), Wahrscheinlichkeitslogik als Form wissenschaftlichen Denkens. In Actes du Congrès international de philosophie scientifique, Paris, 1935. Vol IV: Induction et probabilité. Paris: Hermann, 24-30.

[26] Reichenbach, H. (1936c), Logistic Empiricism in Germany and the Present State of its Problems. The Journal of Philosophy, 33(6):141-160.

[27] Reichenbach, H. (1937), Les fondements logiques du calcul des probabilités. Annales de l'Institut Henri Poincaré, 7(5):267-348.

[28] Reichenbach, H. (1949), The Theory of Probability. An Inquiry into the Logical and Mathematical Foundations of the Calculus of Probability. BerkeleyLos Angeles: University of California Press.

[29] Reichenbach, H. (1956), The Direction of Time. Berkeley-Los Angeles: University of California Press.

[30] Reichenbach, H. (1959), Modern Philosophy of Science: Selected Essays. M. Reichenbach (ed.), London: Routledge \& Kegan Paul. 
[31] Reichenbach, H. (1978), Selected Writings: 1909-1953, 2 Volumes. Cohen, R. \& M. Reichenbach (eds.), Dordrecht-Boston: Reidel.

[32] Reichenbach, H. (2006), Defending Einstein: Hans Reichenbach's Writings on Space, Time and Motion. Gimbel, S. \& A. Walz (eds.), New York: Cambridge University Press.

[33] Richardson, A.W. (1998), Carnap's Construction of the World. The Aufbau and the Emergence of Logical Empiricism. Cambridge-New York-Melbourne: Cambridge University Press.

[34] Ryckman, T.A. (1991), Conditio sine qua non? Zuordnung in the Early Epistemologies of Cassirer and Schlick. Synthese, 88(1):57-95.

[35] Ryckman, T.A. (2005), The Reign of Relativity. Philosophy in Physics 19151925. New York: Oxford University Press.

[36] Schlick, M. (1918), Allgemeine Erkenntnislehre. Berlin: Springer, 2nd rev. ed. 1925. Translated as General Theory of Knowledge, Feigl H. \& A. Blumberg (eds.), LaSalle (Ill.): Open Court, 1974.

[37] Schlick, M. (1921), Kritizistische oder empiristische Deutung der neuen Physik? Bemerkungen zu Ernst Cassirers Buch 'Zur Einsteinschen Relativitätstheorie'. Kant-Studien, 26:96-111. Translated as "Critical or Empiricist Interpretation of Modern Physics?” In Mulder, H. \& B. van de Velde-Schlick (eds.), Moritz Schlick, Philosophical Papers. Vol. II. Dordrecht: Reidel, 1979. 